$$
\begin{aligned}
& \text { Frengklin Matatula \& Rosmiati. Pengembangan Website dan Sistem Informasi Desa } \\
& \text { di Desa Pangkan Kecamatan Paku Kabupaten Barito Timur. }
\end{aligned}
$$

\title{
PENGEMBANGAN WEBSITE DAN SISTEM INFORMASI DESA DI DESA PANGKAN KECAMATAN PAKU KABUPATEN BARITO TIMUR
}

\author{
Frengklin Matatula, S.Kom,MMSI, Rosmiati, M.Kom \\ Stmik Palangkaraya JI G.Obos II 4 Menteng, Kec. lekan Raya, Kota Palangka Raya, \\ Kalimantan Tengah 74874 \\ Telp/Fax : 0536-3224593/ 0536-32255I5 \\ Email : rfrengklin@gmail.com, fayadhah@gmail.com
}

\begin{abstract}
Currently the world of information is growingrapidly, characterized by the use of village websites for the introduction of the village, the website as a presenter of information on its existence has now become a necessity. The benefits of the internet are quite large felt especially in the world of business, entertainment and education and also government. Pangkan village is one of the villages located in Paku District of East Barito district. Pangkan Village is an Internal Government Agency engaged in community service experiencing obstacles in the system of introduction of organizational structures, activities, locations, which are currently only known by the surrounding community. Withthe development of Informasi Technology, encouraging the Author to design the Pangkan Village Profile website with the authorof thiswebsite is expected to run well it will make it easier to introduce the potentials, activities,di Desa pangkan And the community can know the developments that occur in the village, especially the community around the village pangkan and more broadly can be known by all communities in the world. The purpose of this research is to build a website Profile of pangkan Village, PakuSubdistrict, East BaritoRegency. The benefit of this research is that in addition to those listed above it is expected that the webiste in the village can optimize in conveying information about the potential organizational structure in the village. This research method is information gathering, data analysis, design, programming, trial and implementation. With the construction of the profile website of the village, it is easier to introduce the village so that it can be known by the wider community, especially the people of the village pangkan do not have to come directly to the village pangkan enough to see through wesite can find out the information in the village pangkan
\end{abstract}

Keywords: Website, Pangkan Village

\begin{abstract}
ABSTRAK
Saat ini dunia informasi berkembang dengan pesat, ditandai dengan adanya pemanfaatan website desa guna pengenalan desa tersebut, website sebagai penyampai informasi keberadaannya kini sudah menjadi kebutuhan. Manfaat internet cukup besar dirasakan terutama dalam dunia bisnis, hiburan dan pendidikan dan juga pemerintahan. Desa pangkan adalah salah satu desa yang terdapat di Kecamatan Paku kabupaten Barito Timur. Desa Pangkan adalah suatu Instansi Pemerintahan Dalam Negeri yang bergerak di bidang pelayanan masyarakat mengalami kendala dalam sistem pengenalan struktur organisasi, kegiatan - kegiatan, lokasi, yang saat ini hanya dikenal oleh masyarakat sekitar saja. Dengan perkembangan Teknologi Informasi, mendorong Penulis untuk merancang website Profil Desa Pangkan dengan pembuatan website ini diharapkan berialan dengan baik maka akan mempermudah dalam mengenalkan potensi - potensi, kegiatan,di Desa pangkan Serta masyarakat dapat mengetahui perkembangan yang teriadi Di Desa pangkan khususnya masyarakat sekitar Desa pangkan dan lebih luasnya dapat dikenal Oleh seluruh masyarakat di Dunia. Tujuan penelitian ini adalah membangun website Profil Desa pangkan, Kecamatan Paku, Kabupaten Barito Timur. Manfaat dari penelitian ini adalah selain yang tertera diatas diharapkan dengan adanya webiste pada Desa pangkan dapat mengoptimalkan dalam menyampaikan informasi tentang stuktur organisasi potensi yang ada di Desa pangkan. Metode penelitian ini pengumpulan informasi,analisis data, perancangan, pemograman, uji coba dan implementasi. Dengan dibangunnya website profil Desa pangkan mempermudah dalam memperkenalkan Desa pangkan sehingga dapat dikenal oleh masyarakat luas khususnya masyarakat Desa pangkan tidak harus datang langsung ke Desa pangkan cukup melihat melalui wesite bisa mengetahui informasi yang ada di Desa pangkan
\end{abstract}

Kata Kunci : Website, Desa Pangkan

\section{PENDAHULUAN}

Pembangunan Desa Saat Ini Tidak Terlepas Dari Perkembangan Teknologi Informasi Dari Awal Sesederhana Menggunakan Telepon Seluler Ke Ponsel Cerdas Atau (Smartphone)
Gunakan Internet Dengan Berbagai Fungsi Yang Ditujukan Untuk Bantu Komunitas Melakukannya Tidak Hanya Aktivitas Sehari-Hari Di Kota, Tapi Di Pedesaan. Teknologi Informasi Dan Komunikasi 
Memberikan Banyak Manfaat Kehidupan Manusia Adalah Salah Satunya Sederhanakan Hal-Hal Seperti Huruf Komunikasi Media Sosial Dan Promosi Hasil Pertanian Dapat Dilakukan Dengan Bantuan Teknologi Informasi Membuat Informasi Dikirim Dapat Diakses Masyarakat Desa Dan Kota. Kurangnya Pemahaman Masyarakat Dan Peralatan Pedesaan Yang Terkait Dengan Teknologi Informasi Mengarah Ke Layanan Masyarakat Belum Optimal. Peralatan Pelayanan Pemerintah Desa Orang Harus Bisa Menguasai Teknologi Informasi Sehingga Server Masyarakat Bisa Dioptimalkan.

Pemerataan kesejahteraan di wilayah desa pangkan belum sepenuhnya

baik dan pemerataan teknologi juga berdampak pada kurangnya informasi mengenai desa masih sangat sedikit. Desa Pangkan yang berada diKecamatan Paku Kabupaten Barito Timur dengan luas wilayah $4.500 \mathrm{Ha}$. Terdiri dari $3 \mathrm{RT}$ jarak dari Desa Pangkan kecamatan Paku $12 \mathrm{Km}$ jarak dari kabupaten Barito Timur $60 \mathrm{KM}$, jarak ke ibu kota provinsi di Palangkaraya 300 KM, Namun rendahnya pengetahuan dan pemanfaatan teknologi informasi bagi pemerintah desa setempat membuat pemanfaatan teknologi informasi dalam memberikan pelayanan kepada masyarakat kurang efektif.

Kebutuhan akan informasi dan teknologi bagi masyarakat desa sangat besar tetapi karena kurangnya pengetahuan akan teknologi informasi maka informasi yang didapat belum maksimal dengan adanya penerapan sistem informasi berbasis website ini diharapkan akan memberikan kemudahan kepada masyarakat untuk mengakses informasi secara cepat dan akurat yang sesuai dengan kebutuhan masyarakat.

I.2 Rumusan Masalah

Berdasarkan latar belakang yang telah diuraikan diatas maka diperoleh rumusan masalah yang ada didesa Pangkan Kecamatan Paku kabupaten Barito Timur yaitu “ Bagaimana merancang dan membangun sistem informasi Desa Pangkan Berbasis website?

\section{I.3 Batasan Masalah}

Batasan masalah diberikan agar penelitian tidak meluas dari yang akan dibahas. Adapun beberapa batasan masalah yaitu sebagai berikut :

I. Aplikasi yang dibuat berbasis Website

2. Aplikasi ini menggunakan database MySql dan bahasa pemprograman PHP

3. Situs ini terdiri dari sejarah desa, visi, misi peta wilayah, struktur organisasi desa, perangkat desa, data desa

I.4 Tujuan
Penelitian ini bertujuan untuk membuat profil desa Pangkan Kecamatan Paku Kabupaten Barito Timur yang dapat diakses melakui website

\section{LANDASAN TEORI}

2.I Sejarah Internet Dunia

Internet merupakan jaringan komputer yang dibentuk oleh Departemen Pertahanan Amerika Serikat di tahun 1969, melalui proyek ARPA yang disebut ARPANETI (Advanced Research Project Agency Network), dimana mereka mendemonstrasikan bagaimana dengan hardware dan software komputer yang berbasis UNIX, kita bisa melakukan komunikasi dalam jarak yang tidak terhingga melalui saluran telepon. Proyek ARPANET merancang bentuk jaringan, kehandalan, seberapa besar informasi dapat dipindahkan, dan akhirnya semua standar yang mereka tentukan menjadi cikal bakal pembangunan protokol baru yang sekarang dikenal sebagai TCP/IP (Transmission Control Protocol/Internet Protocol).

Pada tahun 1987 berdirilah sebuah ISP (internet service profvider)x yang di beri nama UUNet yang pada saat itu merupakan provider utama internet. Seiring berjalannya waktu, aplikasi internet semakin bertambah dengan diciptakannya WAIS ( wide area information server ), Gopher, dan WWW (World wide web)

2.I Pengertian Website atau Situs

Menurut Febrin Aulia Batubara (2015:17) Website atau situs dapat diartikan sebagai kumpulan halaman-halaman yang digunakan untuk menampilkan informasi teks, gambar diam atau gerak, animasi, suara, dan atau gabungan dari semuanya baik yang bersifat statis maupun dinamis yang membentuk satu rangkaian bangunan yang saling terkait, yang masing-masing dihubungkan dengan jaringan-jaringan halaman. Hubungan antara satu halaman web dengan halaman web yang lainnya disebut hyperlink, sedangkan teks yang dijadikan media penghubung disebut hypetext.

Menurut Eri Bowo (20|4:2) Website adalah halaman informasi yang disediakan melalui jaringan internet. Website merupakan komponen atau kumpulan komponen yang bisa terdiri dari teks, gambar, suara, video, animasi, dan lain sebagainya.

Berdasarkan kajian di atas dapat disimpulkan web adalah kumpulan halamanhalaman yang digunakan untuk menampilkan informasi teks, gambar diam atau gerak, animasi, suara, dan atau gabungan dari semuanya itu baik yang bersifat statis maupun dinamis yang membentuk satu rangkaian bangunan yang saling terkait di mana masing-masing dihubungkan dengan jaringan-jaringan halaman (hyperlink). 
di Desa Pangkan Kecamatan Paku Kabupaten Barito Timur.

\subsection{Hypertext Preprocessor (PHP)}

Menurut Abdul Kadir (2013:17), PHP adalah bahasa pemrograman yang ditujukan untuk kepentingan pembuatan aplikasi web. Sebagai bahasa pemrograman untuk web, PHP sebenarnya bukanlah satu-satunya, tetapi termasuk yang populer. PHP memungkinkan pembuatan aplikasi web yang dinamis, dalam arti, dapat membuat halaman web yang dikendalikan oleh data. Dengan demikian, perubahan data akan membuat halaman web ikut berubah tanpa harus mengubah script atau kode yang menyusun halaman web.

Menurut Arief (2011:43), PHP adalah Bahasa Server Side-Scripting yang menyatu dengan HTML untuk membuat halaman web yang dinamis. Karena PHP merupakan server side-scripting, maka sintaks dan perintah-perintah PHP akan di eksekusi di server, kemudian hasilnya akan dikirimkan ke browser dengan format HTML.

Berdasarkan kajian menurut pakar di atas maka dapat disimpulkan bahwa PHP merupakan bahasa pemrograman yang digunakan untuk membangun sebuah web. PHP disimpan pada server yang digunakan oleh klien untuk ditampilkan pada browser

\subsection{Bootstrap}

Menurut Eko Priyo Utomo (2016:1I) Bootstrap merupakan salah satu Framework HTML, CSS,dan JS yang cukup populer, serta banyak digunakan oleh para pengembang Web saat ini. Framework ini banyak digunakan untuk membuat Website yang bersifat responsif. Artinya bisa menyesuaikan tampilan layout nya berdasarkan ukuran Viewport dari Device pengaksesannya, mulai dari Smartphone, Tablet, atau layar PC.

\section{$2.4 \mathrm{MySql}$}

Menurut Madcoms Madiun (2016:152) MySQL adalah salah satu jenis database server yang sangat terkenal MySQL menggunakan Bahasa SQL untuk mengakses database-nya. Lisensi MySQL adalah FOSS License Exeption dan ada juga yang versi komersial.

2.5 XAMPP

Menurut Madcoms Madiun (2016:186) XAMPP adalah sebuah paket kumpulan Software yang terdiri dari Apache, MySQL, phpMyAdmin PHP,Perl, FileZilla, dan lain-lain XAMPP berfungsi untuk memudahkan instalasi lingkungan di PHP, di mana biasanya lingkungan pengembangan Web memerlukan PHP Apache, MySQL, dan
phpMyAdmin serta Software yang terkait dengan pengembangan Web

\subsection{Sublime Text}

Sublime Text adalah aplikasi editor untuk kode dan teks yang dapat berjalan diberbagai platform operating system dengan menggunakan teknologi Phyton API. Sublime Text mendukung berbagai Bahasa pemrograman dan mampu menyajikan fitur syntax highlight hamper semua Bahasa pemrograman yang di dukung ataupun dikembangkan oleh komunitas seperti $\mathrm{C}, \mathrm{C}++, \mathrm{C}=$, CSS, D, Dylan, Erlang, HTML, Groovy, Haskell, Java, JavaScript, LaTeX, Lisp, Lua, Markdown, MATLAB, OCaml, Perl, PHP, Phyton, R, Ruby, SQL, TCL, Textile, and XML.

\section{METODE PENELITIAN}

\section{I Metode Pengembangan Sistem}

Penelitian ini menggunakan pendekatan pengembangan model Waterfall. Model Waterfall merupakan salah satu model pengembangan perangkat lunak yang ada di dalam model SDLC (Sequencial Development Life Cycle). Menurut Sukamto dan Shalahuddin (2013:26) bahwa "SDLC atau Software Development Life Cycle atau sering disebut juga System Development Life Cycle adalah proses mengembangkan atau mengubah suatu sistem perangkat lunak dengan menggunakan model-model dan metodologi yang digunakan orang untuk mengembangkan sistem-sistem perangkat lunak sebelumnya, berdasarkan best practice atau cara-cara yang sudah teruji baik.

Sedangkan Sukamto dan Shalahuddin (2013:28) di jelaskan bahwa model waterfall sering juga disebut model sekuensi linear atau alur hidup klasik. Pengembangan sistem dikerjakan secara terurut mulai dari analisis, desain, pengkodean, pengujian dan tahap pendukung.

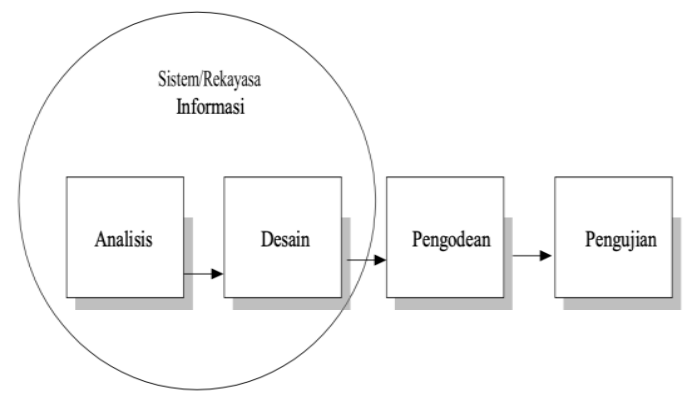

Gambar I Tahap Proses Waterfall

(Sumber :Sukamto dan Shalahuddin (2013) 
4. HASIL DAN PEMBAHASAN

Gambar 2 Struktur menu
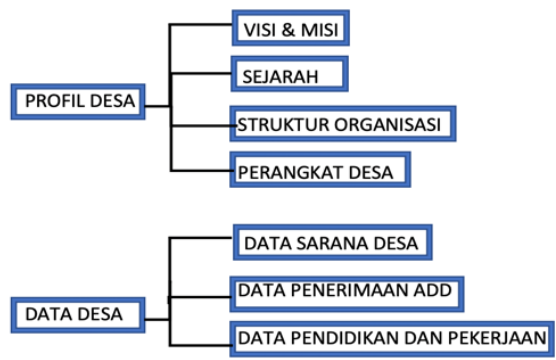

\section{BERITA DESA}

DOWNLOAD

PENGUMUMAN

Menu Tampilan depan

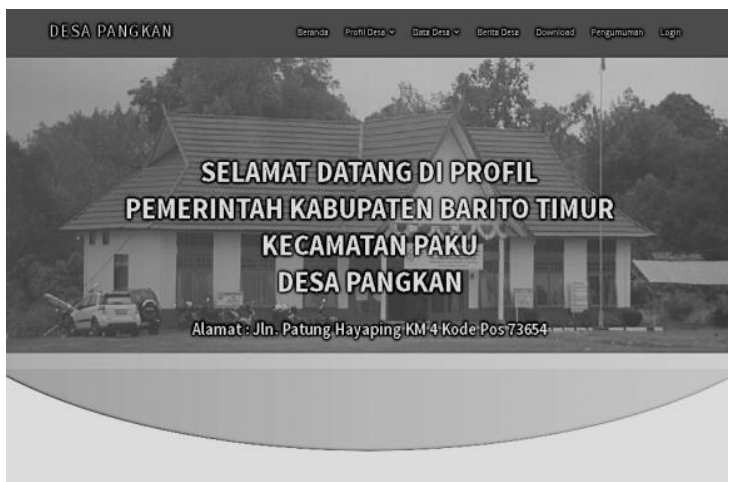

Gambar 3. Tampilan Depan Website

Tampilan Menu Depan Website

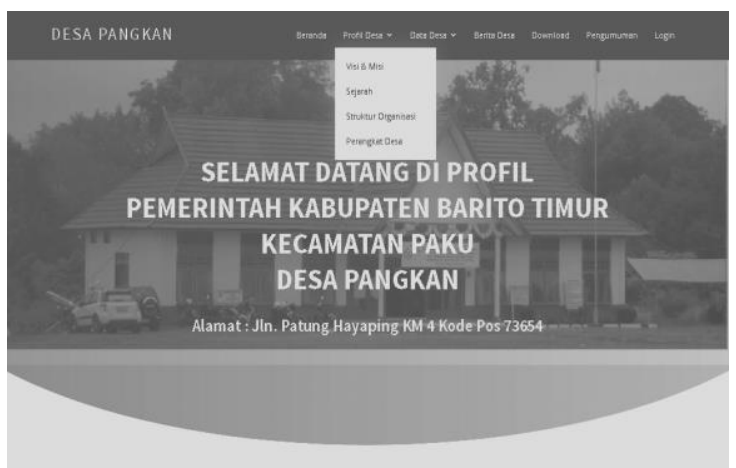

Gambar 4. Tampilan Menu Profil Desa

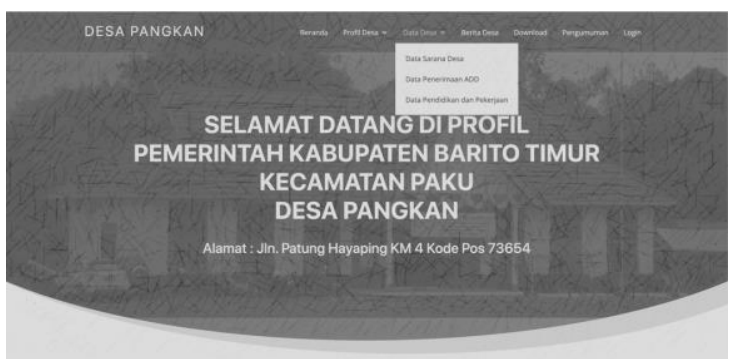

Gambar 5. Tampilan Menu Data Desa
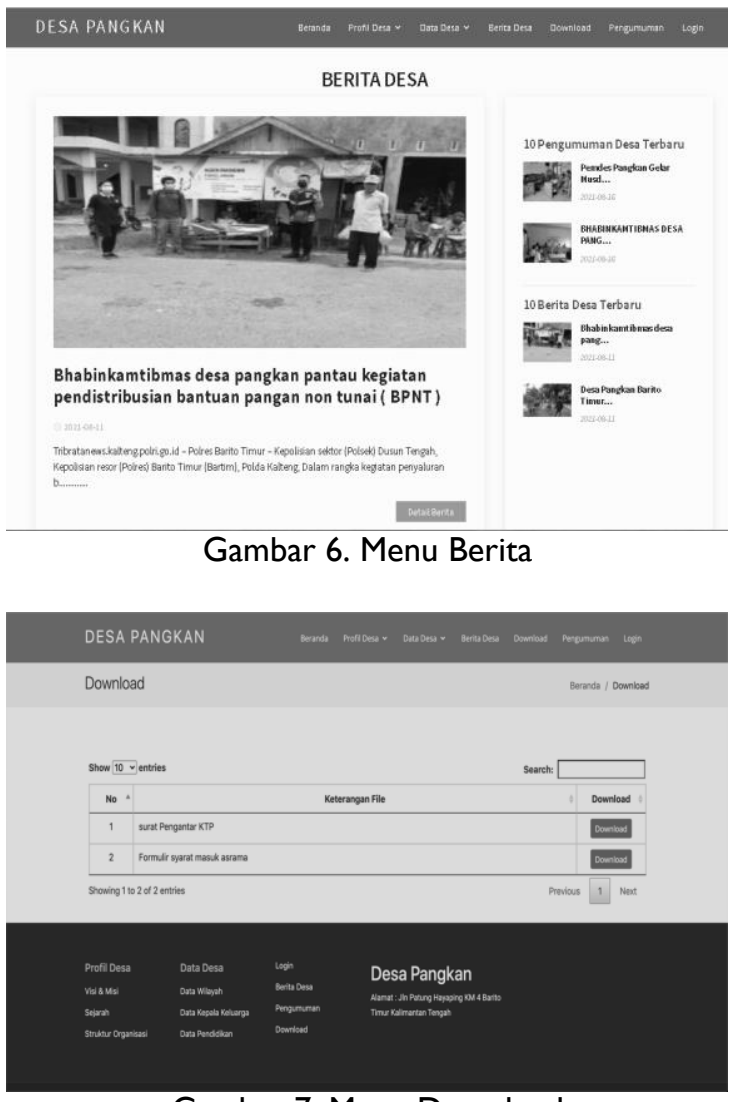

Gambar 7. Menu Download

Tampilan Administrasi Desa

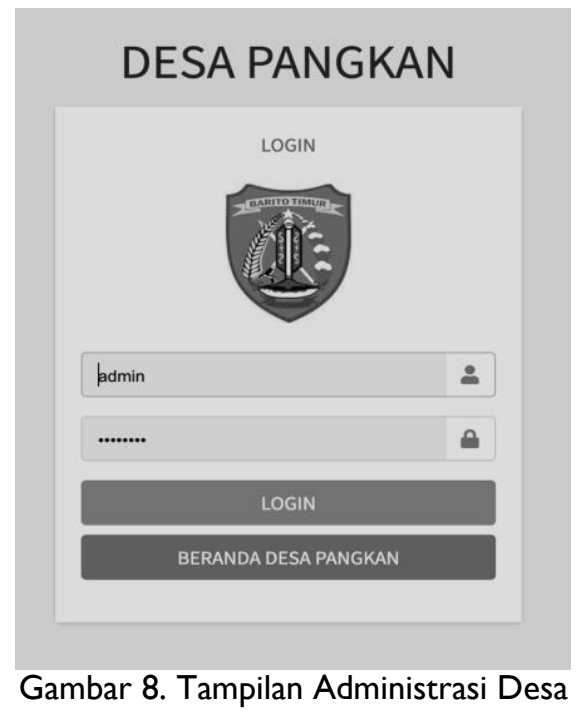

Gambar 8. Tampilan Administrasi Desa 
di Desa Pangkan Kecamatan Paku Kabupaten Barito Timur.

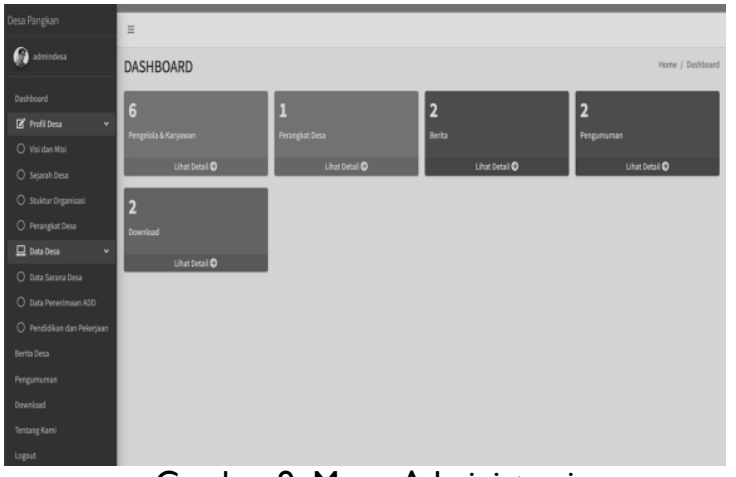

Gambar 9. Menu Administrasi

\section{KESIMPULAN DAN SARAN}

Penelitian ini menghasilkan sebuah website profil desa Pangkan yang mana Kebutuhan akan informasi dan teknologi bagi masyarakat desa pangkan yang sangat besar tetapi karena kurangnya pengetahuan akan teknologi informasi maka informasi yang didapat belum maksimal dengan adanya penerapan sistem informasi berbasis website ini diharapkan akan memberikan kemudahan kepada masyarakat untuk mengakses informasi secara cepat dan akurat yang sesuai dengan kebutuhan masyarakat.

\section{TERIMA KASIH}

Ucapan terima kasih peneliti sampaikan terutama kepada pemerintah desa Pangkan Kecamatan Paku Kabupaten Barito Timur dan masyarakat desa yang telah memberikan dukungan kepada peneliti dalam membangun website profil desa ini.

\section{DAFTAR PUSATAKA}

I. Brien, J. O., \& Markas, G. (20II). Management Information System (Vol. IOth). Cegielski, R. P. (20/5). Introduction to Information System. John Wiley and Sons.Coronel, C., \& Morris, S. (2015). Database Systems: Design, Implementation, \& Management (Vol. IIth). Cengage Learning.

2. Edi Noersasongko dan Pulung Nurtantio Andono,20l0.Mengenal Dunia Komputer.Jakarta: PT Elex Media Komputindo,hal I9I.

3. Iskandar, 2009. Panduan Lengkap Internet. Yogyakarta:Andi Offset, hal 62 Marimin, Tanjung, H. \& Prabowo, H. (2006). Sistem Informasi Manajemen Sumber Daya Manusia. Jakarta: Grasindo.
4. McLeod, R., Ir. (200I). Sistem Informasi Manajemen. Jilid I dan 2. Jakarta: Prenhallindo.

5. McLeod, R., Ir. \& Schell, G. (2004). Sistem Informasi Manajemen. Jakarta: Prenhallindo.

6. O'Brien, I.A. (2004). Management Information System: Managing Information Technology in the Internetworked Enterprise. 4 th Edition. Boston: Irwin McGraw-Hill.

7. Rahmat Hidayat,20I0, Cara Praktis Membangun Website Gratis. Jakarta: PT Elex Media Komputindo, hal 2.

8. Wahtu Supriyanto- Ahmad Muhsin, 2008. Teknologi Informasi Perpustakaan. Yogyakarta: Kanisius, hal 61. Manfaat internet, Iskandar, 2009

9. Yuhefizar, 2008. 10 Jam Menguasai Internet. Jakarta: Elex Media Komputindo, hal I. pengertian internet secara umum. 